Abanico Veterinario. Enero-Diciembre 2021; 11:1-13. http://dx.doi.org/10.21929/abavet2021.5 Artículo Original. Recibido: 28/08/2020. Aceptado: 15/01/2021. Publicado: 30/01/2021. Clave:2020-74.

\title{
Identificación del Mycobacterium avium subsp. paratuberculosis y su seroprevalencia en rebaños ovinos de Aguascalientes
}

\author{
Mycobacterium avium subsp. paratuberculosis identification and seroprevalence in \\ sheep flocks in Aguascalientes
}

\section{Pallás-Guzmán Gabriel1 ID, Quezada-TristánTeódulo1 ID, Chávez-Gris Gilberto² ID , Maldonado-Castro Edith ${ }^{2}$ ID, Chávez-González Leticia ${ }^{11 D}$, García-Munguía Carlos³ID}

${ }^{1}$ Centro de Ciencias Agropecuarias, Universidad Autónoma de Aguascalientes. Av Universidad 940, col. Ciudad Universitaria, CP 20131, Aguascalientes, Aguascalientes. México. ${ }^{2}$ Facultad de Medicina Veterinaria y Zootecnia (CEIEPAA), UNAM. Carretera Federal Tequisquiapan a, Ezequiel Montes Km 8.5, CP 76790, Tequisquiapan, Querétaro, México. ${ }^{3 *}$ Autor para la correspondencia: García-Munguía Carlos, Departamento de Veterinaria y Zootecnia, Universidad de Guanajuato. Carretera Irapuato-Silao km 9, CP 36500 Irapuato, Guanajuato, México. cagamu@hotmail.com, gepallas@correo.uaa.mx, tequezada@correo.uaa.mx,gris@unam.mx, edithmc@unam.mx, Ichavezglz@hotmail.com

\section{RESUMEN}

Con el objetivo de identificar la presencia de Paratuberculosis (PTB), enfermedad infecciosa causada por el Mycobacterium avium subsp paratuberculosis (MAP), en ovinos, a través de estudios anatomopatológicos, cultivo bacteriano y PCR IS900, así como estimar la seroprevalencia a MAP. El presente estudio, de tipo transversal, se realizó en 16 diferentes rebaños con el suero de 2415 animales adultos y analizados por Ensayo por Inmunoabsorción Ligado a Enzimas (ELISA); se emplearon nueve ovinos con signos clínicos sugerentes a PTB, de los cuales se obtuvieron muestras para la realización de los estudios de identificación; obteniendo un $51.3 \%$ de animales seropositivos a MAP (1239/2415), en el $100 \%$ de los rebaños (16/16); el aislamiento bacteriano y su identificación por PCR IS 900 en cinco de los nueve casos hallados (5/9) correspondiendo al $31.25 \%$ de los rebaños (5/16). Conformando la presencia del Mycobacterium avium subsp paratuberculosis, así como una elevada frecuencia de animales seropositivos a MAP en rebaños de Aguascalientes.

Palabras clave: Paratuberculosis, ovinos, seroprevalencia, Mycobacterium.

\begin{abstract}
With the objective of identifying the presence of Paratuberculosis (PTB), an infectious disease caused by Mycobacterium avium subsp paratuberculosis (MAP), in sheep, through pathological studies, bacterial culture and IS900 PCR, as well as estimating seroprevalence to MAP. The present cross-sectional study, was conducted in 16 different flocks, with the serum of 2415 adult sheeps, and analyzed by Enzyme-Linked ImmunoSorbent Assay (ELISA); nine sheep were used with clinical signs suggestive of PTB, from which samples were obtained for the identification studies; obtaining $51.3 \%$ of animals seropositive to MAP (1239/2415), in $100 \%$ of the herds (16/16); Bacterial isolation and its identification by PCR IS900 were founded in five of the nine cases (5/9) corresponding to $31.25 \%$ of the herds (5/16). Confirming the presence of Mycobacterium avium subsp paratuberculosis, and a high frequency of seropositive animals to MAP in flocks of Aguascalientes.
\end{abstract}

Keywords: Paratuberculosis, sheep, seroprevalence, Mycobacterium. 


\section{INTRODUCCIÓN}

La paratuberculosis (PTB) o Enfermedad de Johne (EJ), es una enfermedad crónica infecciosa que ocasiona una enteritis granulomatosa en los rumiantes y eventualmente otras especies, con una amplia distribución mundial; causada por el Mycobacterium avium subsp. paratuberculosis (MAP) (Coelho et al., 2010). Clasificada por la Organización Mundial de Sanidad Animal (OIE) como una enfermedad transmisible, con impacto socioeconómico y en la salud pública, sugiriéndose la participación de MAP en la enfermedad de Crohn en humanos (OIE, 2017; Balseiro et al., 2019; Gioffré et al., 2015). Del MAP se han descrito tres diferentes cepas la tipo I (Sheep), la tipo II (Cattle) y la tipo III (Bisón o intermedia), de acuerdo a su preferencia por infectar diferentes especies de rumiantes y sus distintos requerimientos para su aislamiento bacteriano (Begg y Whittington, 2010; Windsor, 2015). La enfermedad se caracteriza por presentar signos de emaciación progresiva, edema submandibular y eventualmente la muerte de los animales. La principal vía de infección es la fecal-oral, con un periodo de incubación que oscila de uno a cuatro años, por lo que pueden llegar a observarse signos de la enfermedad a partir del año de vida (Chávez et al., 2004), una vez que MAP ingresa al intestino se aloja en los macrófagos constituyendo una infección granulomatosa donde se pueden observar cantidades variables de bacterias (Begg y Whittington, 2010; Windsor, 2015). El diagnóstico, prevalencia e impacto de la enfermedad son escasos y no concluyentes tanto en América Latina como en México (Chávez et al., 2004; Begg y Whittington, 2010; Fernández et al., 2014).

En México, se ha detectado la presencia de PTB en ovinos en diversos estados del país, como son, San Luis Potosí, Guanajuato, Querétaro, Ciudad de México, Estado de México y Veracruz (Estévez et al., 2006). Particularmente, en el Estado de Aguascalientes, la actividad de la ovinocultura como en otros estados del país ha crecido a partir de 1990 en más del $100 \%$, con una producción cárnica de aproximadamente 612 toneladas en el 2018, siendo la zona Valle, conformado por los municipios de Aguascalientes, San Francisco de los Romo, Rincón de Romos, Jesús María, Pabellón de Arteaga y Asientos, en donde se concentra el $85 \%$ de la producción de carne ovina del Estado y de la actividad pecuaria en general (SIAP, 2018).

Es de suma importancia resaltar que en esta región no se cuenta con registros del diagnóstico e identificación de las enfermedades que son capaces de afectar a los rebaños ovinos y el efecto adverso que éstas pueden causar en la productividad. Pues en el Estado de Aguascalientes existen casos no cuantificados de animales adultos con emaciación progresiva y mortalidad, sin embargo, no se realiza un diagnóstico y es imposible determinar si esta la PTB.

Por lo anterior, el objetivo del presente trabajo es identificar la presencia de MAP a través de estudios anatomopatológicos, cultivo y PCR en ovinos con cuadro clínico sugerente a PTB, así como determinar la seroprevalencia contra MAP mediante ELISA en rebaños ovinos del Valle de Aguascalientes. 


\section{Diseño del estudio}

\section{MATERIAL Y MÉTODOS}

Este estudio de tipo descriptivo-transversal fue realizado en el Estado de Aguascalientes, México, siendo los rebaños y animales de estudio seleccionados de acuerdo con el método no probabilístico "por conveniencia" (Trusfield, 2018). De esta manera, fueron seleccionados 16 rebaños ovinos con poblaciones que oscilaron entre 60 y 340 individuos, conformando una población total de estudio de 2,415 animales (Figura 1 y Tabla 1), donde se requería que el rebaño contara con signos clínicos de emaciación progresiva crónica sugerente a PTB en al menos un ejemplar mayor a un año; considerando a cada rebaño como unidad experimental.

\section{Toma de muestras}

Suero sanguíneo. Se obtuvieron $5 \mathrm{~mL}$ de sangre por venopunción de la yugular, la cual fue captada en tubos sin aditivo para la obtención del suero; posteriormente las muestras fueron almacenadas $\mathrm{a}-20^{\circ} \mathrm{C}$ hasta su empleo en la prueba ELISA.

ELISA. Los sueros previamente obtenidos, se analizaron mediante la prueba de inmunoensayo enzimático indirecto (ELISA) empleando el antígeno protoplasmático PPA3 (Allied, Mo.), el cual presenta una especificidad del $75 \%$ y una sensibilidad del $64 \%$ de acuerdo con el protocolo empleado por García (1992).

Obtención de muestras para estudio histopatológico y aislamiento de MAP. Tomando como referencia a Timoney (1988) y observando el curso clínico de los animales y las características epidemiológicas de los 9 rebaños, se logró establecer un diagnóstico presuntivo en 9 animales; los cuales presentaron signos de emaciación progresiva, pelo o lana hirsuta, edema submandibular, lesiones y heces blandas. Entendiendo así, que el $56.25 \%$ de los rebaños de estudio, presentaron al menos un caso sugerente a PTB.

Posteriormente los 9 animales fueron sacrificados con una sobredosis de pentobarbital sódico (NOM-033-SAG/ZOO-2014) de acuerdo a los lineamientos establecidos en el "Comité de ética para el uso de animales en la docencia e investigación de la Universidad Autónoma de Aguascalientes".

La confirmación de estos casos se realizó por medio de necropsia e identificación de lesiones, descartando así la presencia de posibles lesiones sugerentes a diagnósticos diferenciales de pseudotuberculosis (Corynebacterium pseudotuberculosis), alteraciones digestivas por presencia de cuerpos extraños, neoplacias, neumonías crónicas y parasitosis severa, (Straub, 2004; Windsor, 2014).

Posterior a ello, se tomaron muestras de secciones intestinales de íleon y yeyuno, las cuales mostraron engrosamiento de la mucosa intestinal que sugerían lesiones asociadas a paratuberculosis; estas secciones fueron fijadas en formalina amortiguada ( $\mathrm{pH}$ 7.6) para su posterior procesamiento histológico, empleando las tinciones de Hematoxilina-Eosina $(\mathrm{H}-\mathrm{E})$ y de Ziehl-Neelsen (ZN), esta última con la finalidad de evidenciar la presencia de bacilos ácido alcohol resistentes (BAAR) (Estévez, 2006). De igual manera, se obtuvieron 
muestras para aislamiento bacteriano a partir de secciones de $30 \mathrm{~cm}$ de íleon y yeyuno que mostraban lesiones sugerentes de PTB (Chávez et al., 2004; Dennis et al., 2011), siendo depositadas en recipientes estériles de plástico para su conservación a -20ㄷ hasta su procesamiento en el laboratorio.

Cultivo Bacteriano a partir de intestino. A su vez, a las muestras tomadas de intestino se les realizó un raspado de la mucosa intestinal con bisturí estéril, procesándolas para descontaminación y concentración de las micobacterias, de acuerdo con la metodología descrita por Sánchez y Guerrero, 2006. Posteriormente, del material de la interfase obtenida, fue inoculado en los medios de cultivo de Löwentein-Jensen (L-Jm) con micobactina, colocando tres a ocho gotas de cada una de las muestras, distribuyéndose en toda la superficie del medio. De cada muestra, se inocularon en dos diferentes tubos con medio L-Jm, uno conteniendo micobactina y el segundo sin micobactina. Posteriormente fueron incubados a $37^{\circ} \mathrm{C}$, manteniéndolos en posición inclinada y sin humedad. Se verificó el crecimiento bacteriano cada cuatro semanas hasta la semana doce, los medios donde no se observó crecimiento, continuaron en incubación hasta la semana 40 (De Juan et al., 2006; Whittington, 2010).

$P C R$ IS900. La identificación molecular se realizó a partir del crecimiento de las colonias de MAP, por medio de PCR punto final, empleando los iniciadores IS900P3N (5'-GGG TGT GGC GTT TTC CTT CG-3') e IS900P5N (5'-ATTTCGCCGCCACCGCCACG-3') (Chávez et al., 2004).

Estimación de la seroprevalencia. La prevalencia se estimó con base en la proporción de animales que resultaron positivos en la prueba de ELISA, con relación a la población total de animales adultos en cada uno de los rebaños. La información generada en el estudio se evaluó y contrastó mediante pruebas de Estadística Descriptiva, mediante "Análisis para una variable", con apoyo del paquete "Statgraphics Centurion XV" TM (Fernández et al., 2002).

\section{RESULTADOS}

Seroprevalencia. El porcentaje de seroprevalencia promedio de los 16 rebaños, fue de $51.3 \%$, con un valor mínimo de $4.8 \%$ y un valor máximo de $91.33 \%$ con un intervalo de confianza al $95.0 \%$ para la media de: [32.7173, 62.3415]. Los resultados de seroprevalencia individual para cada uno de rebaños se describen la Tabla 1. En los dieciséis rebaños en los que se realizaron las pruebas de ELISA (PPA-3), se identificaron casos positivos, obteniéndose una seroprevalencia calculada a "nivel de rebaño" del 100\% (Tabla 1). 
Estudio anatomopatológico. En los 9 animales a los que se les realizó la necropsia, presentaron emaciación, lana o pelo hirsutos, edema submandibular (Figura 1), presencia de ascitis, degeneración de la grasa, así como engrosamiento aparente de la mucosa intestinal a nivel de íleon y yeyuno (Figura 2), además de aumento de tamaño de linfonodos mesentéricos y fusión de éstos, no encontrándose evidencia de alteraciones - lesiones sugerentes a otra etiología diferencial a las caudas por PTB. A través del estudio histopatológico, se logró observar en 8 de los 9 animales estudiados (88.8\%), la presencia de enteritis, linfadenitis granulomatosas con presencia de macrófagos, células gigantes y presencia de incontables Bacterias Acido-Alcohol Resitentes (BAAR) mediante la tinción de Ziehl-Neelsen (ZN). Determinándose como lesiones de tipo multibacilar (Figura 3). Mientras que en 1 de los 9 animales estudiados (11.2\%) se observó la presencia de lesiones granulomatosas de tipo multifocal con escasa cantidad de bacilos (BAAR) en el interior de macrófagos, coincidente con una lesión tipo paucibacilar.

Tabla 1. Resultados de seroprevalencia (ELISA) a paratuberculosis, necropsias realizada y resultado de aislamiento bacteriano, por rebaño en el Valle de Aguascalientes

\begin{tabular}{|c|c|c|c|c|c|c|}
\hline $\begin{array}{l}\text { Número } \\
\text { de } \\
\text { rebaño }\end{array}$ & $\begin{array}{c}\text { Seroprevalencia } \\
\%\end{array}$ & $\begin{array}{c}\text { Resultados } \\
\text { positivos ELISA- } \\
\text { PPA-3 }\end{array}$ & $\begin{array}{l}\text { Animales } \\
\text { mayores } \\
\text { de } 1 \text { año }\end{array}$ & $\begin{array}{l}\text { Ejemplares con } \\
\text { signos clínicos } \\
\text { sugerentes a } \\
\text { PTB/Necropsia } \\
\text { realizada }\end{array}$ & $\begin{array}{l}\text { Aislamiento } \\
\text { Bacteriano y } \\
\text { PCR positivo }\end{array}$ & $\begin{array}{l}\text { Ubicación por } \\
\text { municipio }\end{array}$ \\
\hline 14 & 91.3 & 168 & 184 & $+/ 1$ & - & $\begin{array}{c}\text { Rincón de } \\
\text { Romos }\end{array}$ \\
\hline 6 & 84.4 & 287 & 340 & $+/ 1$ & + & $\begin{array}{c}\text { Aguascalientes } \\
\text { (sur) }\end{array}$ \\
\hline 3 & 76.3 & 122 & 160 & $+/ 0$ & $\mathrm{Nr}$ & $\begin{array}{l}\text { Rincón de } \\
\text { Romos }\end{array}$ \\
\hline 11 & 73.1 & 117 & 160 & $+/ 1$ & + & Asientos \\
\hline 10 & 64.4 & 125 & 194 & $+/ 1$ & - & Jesús María \\
\hline 9 & 61.4 & 72 & 140 & $+/ 1$ & + & Asientos \\
\hline 4 & 58.6 & 99 & 169 & $+/ 1$ & + & $\begin{array}{c}\text { Aguascalientes } \\
\text { (sur) }\end{array}$ \\
\hline 15 & 56.8 & 50 & 88 & $+/ 1$ & - & $\begin{array}{l}\text { San Francisco } \\
\text { de los Romo C }\end{array}$ \\
\hline 13 & 54.5 & 36 & 66 & $+/ 0$ & $\mathrm{Nr}$ & $\begin{array}{l}\text { Pabellón de } \\
\text { Arteaga }\end{array}$ \\
\hline 16 & 46.7 & 56 & 120 & $+/ 0$ & $\mathrm{Nr}$ & $\begin{array}{c}\text { Aguascalientes } \\
\text { (centro) }\end{array}$ \\
\hline 1 & 43.8 & 35 & 80 & $+/ 1$ & - & Jesús María \\
\hline 8 & 28.3 & 17 & 60 & $+/ 0$ & $\mathrm{Nr}$ & $\begin{array}{l}\text { Pabellón de } \\
\text { Arteaga }\end{array}$ \\
\hline 5 & 12.9 & 8 & 62 & $+/ 0$ & $\mathrm{Nr}$ & $\begin{array}{c}\text { Aguascalientes } \\
\text { (Nte) }\end{array}$ \\
\hline 7 & 9.5 & 31 & 326 & $+/ 0$ & $\mathrm{Nr}$ & $\begin{array}{c}\text { Aguascalientes } \\
\text { (sur) }\end{array}$ \\
\hline 12 & 8.1 & 8 & 99 & $+/ 0$ & $\mathrm{Nr}$ & $\begin{array}{c}\text { San Francisco } \\
\text { de los Romo }\end{array}$ \\
\hline 2 & 4.8 & 8 & 167 & $+/ 1$ & + & $\begin{array}{l}\text { San Francisco } \\
\text { de Los Romo }\end{array}$ \\
\hline 16 & 51.3 & 1239 & 2415 & $16 / 9$ & & TOTAL \\
\hline
\end{tabular}

Nr: No se realizó 


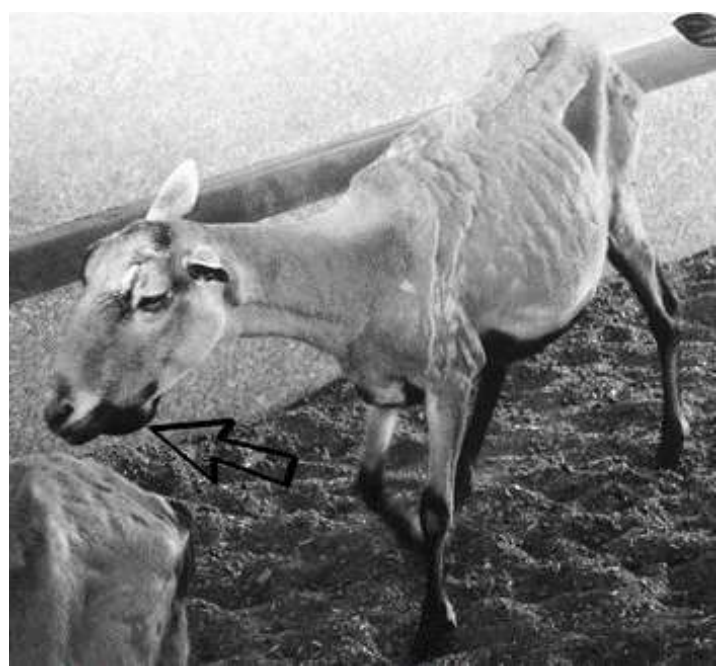

Figura 1. Borrega con signos de emaciación y edema submandibular sugestivos de PTB

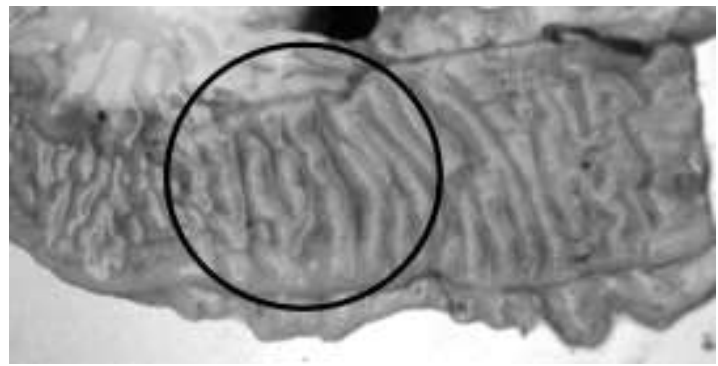

Figura 2. Lesiones macroscópicas correspondientes a engrosamiento intestinal característica de enteritis granulomatosa

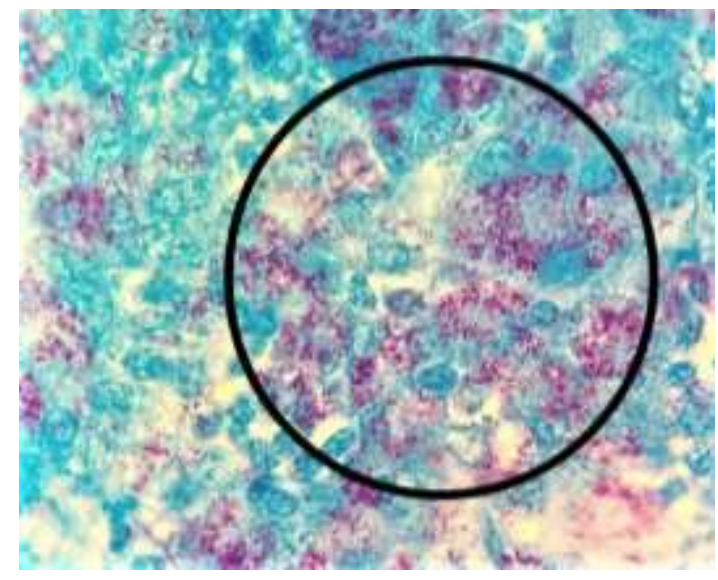

Figura 3. Lesiones Histopatológicas de ID de tipo multibacilar, tinción de Ziehl-Neelsen $400 X$ donde se observan múltiples BAAR en mucosa intestinal 
Aislamiento bacteriano. Después de 12 semanas de incubación se observaron en 5 casos (55.5\%), desarrollo de colonias de color amarillo, cremosas, convexas y de forma circular característicos de MAP en los medios L-Jm adicionados con micobactina. Mientras que en 4 de los casos (44.5\%), no se observó desarrollo de colonias hasta la semana 40. Todos los medios que no fueron adicionados con micobactina, no presentaron crecimiento.

PCR IS900. A partir de los cinco aislamientos bacterianos obtenidos se obtuvieron productos de amplificación de la secuencia IS900 correspondiente a 310 pares de bases (pb), confirmándose así la presencia MAP a partir de estos aislamientos obtenidos (Figura 4).

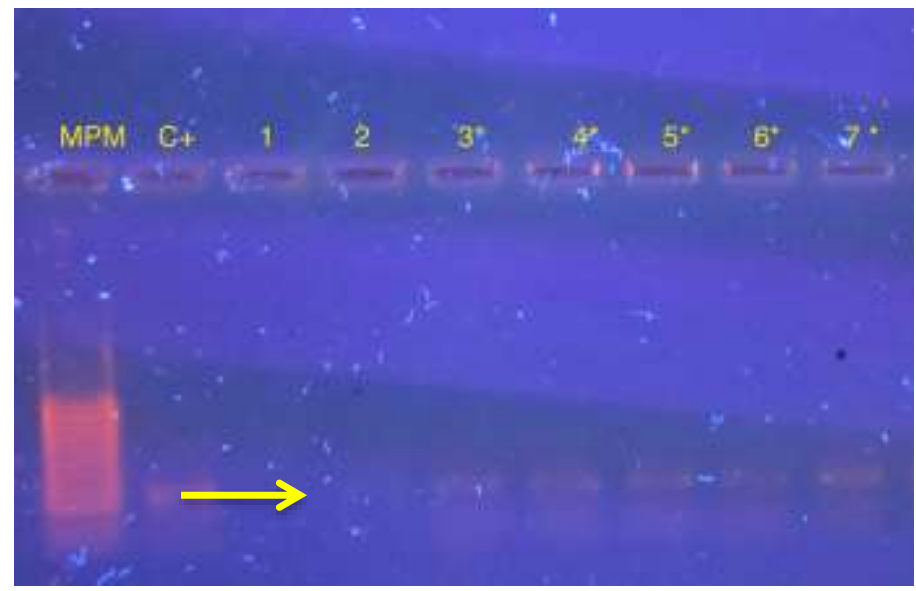

Figura 4. Fotografía de gel de agarosa al $2 \%$ teñido con bromurode etidio. Donde se observan productos de amplificación con un tamaño de $310 \mathrm{pb}$, a partir de ADN de colonias bacterianas obtenidas de tejido intestinal, donde se observa en el carril MPM el marcador de peso molecular $100 \mathrm{pb}, \mathrm{C}+\mathrm{control}$ positivo, carril 1 control negativo (agua), carriles 3 a 7 producto de amplificación obtenidos de los aislamientos 03, 04, 05, 06 y 09, que corresponden a un fragmento de inserción IS 900 de MAP (*).

Es así como en el $100 \%$ de la muestra (16 rebaños de estudio) se obtuvo seropositividad a MAP; a su vez en el $31.25 \%$ de la muestra (5 rebaños) se confirmó la presencia de MAP por aislamiento bacteriano e identificación por PCR IS900 a partir de los animales que presentaron cuadro clínico al momento del estudio (Tabla 2).

Tabla 2. Resultados obtenidos "Por rebaño" correspondientes a los diferentes métodos de diagnóstico e identificación empleados

\begin{tabular}{ccc}
\hline Seropositividad a MAP & $\begin{array}{c}\text { Animales con signos y lesiones a la } \\
\text { necropsia sugerentes a PTB }\end{array}$ & $\begin{array}{c}\text { Aislamiento Bacteriano a partir de } \\
\text { lesiones en Intestino delgado y PCR } \\
\text { IS900 positivo. }\end{array}$ \\
\hline $16 / 16$ & $9 / 16$ & $5 / 16$ \\
$100 \%$ & $56.25 \%$ & $31.25 \%$ \\
\hline
\end{tabular}




\section{DISCUSIÓN}

La seroprevalencia media obtenida en el presente estudio (51.3\%) reporta ser elevada, en comparación a otros estudios realizados de medición de prevalencia tanto en el país como a nivel mundial, considerando que la enfermedad internacionalmente presenta una elevada prevalencia en diferentes especies de rumiantes, con un $20 \%$ y hasta un $40 \%$ (Whittington et al., 2019). En México, diversos estudios indican evidencias serológicas ante MAP como los reportados por Jaimes et al., (2008) en San Luis Potosí, México; donde los resultados de seroprevalencia en ovinos por el método de inmunodifusión en Agar-gel fue de un 44\%. Mientras que en el estado Nayarit se reportó un $28.94 \%$ en ovinos, a través de pruebas de ELISA (Mejía et al., 2015). En Latinoamérica, escasos trabajos realizados en ovinos muestran una amplia variabilidad en la prevalencia a MAP, donde se reportan prevalencias desde un 4.3\% promedio en ovinos (Fernández et al., 2014), hasta un $54.08 \%$ de seroprevalencias a MAP en ovinos en Brasil, (Medeiros et al., 2012).

Ante los escasos estudios, y una amplia variación en cuanto a la metodología y la prueba diagnóstica empleada para la evaluación de la prevalencia a la PTB, Espechit et al. (2017) y Whittington et al., (2019) señalan que esto resulta en una gran variabilidad de los resultados, y por consecuencia, una desestimación de la presencia e impacto verdadero de la paratuberculosis.

A pesar de los resultados obtenidos de una elevada frecuencia, al momento del estudio sólo se encontraron casos clínicos (9/16) en el 56.25\% de los rebaños estudiados, donde la totalidad de ellos muestran lesiones histopatológicas multibacilares o paucibacilares, características de la enfermedad, en donde si se considera que éstas se presentan en individuos mayores a un año de edad, con un tiempo prolongado de infección aunadas a la presentación de un cuadro clínico característico, altamente sugerente a PTB, se pueden llegar a considerar un diagnóstico definitivo de MAP en lo individual, difícilmente descartado por otras pruebas como cultivo y PCR como lo mencionan varios autores (Pérez et al., 1999; Dennis et al., 2011; Windsor, 2015; Whittingtong et al., 2019).

Considerando que los nueve animales a los que se les realizó la necropsia presentaron lesiones características a PTB, sólo en el 55.5\% (5/9) se logró el aislamiento bacteriano a pesar de presentar lesiones de tipo multibacilar en ocho de los nueve. La dificultad del aislamiento de MAP, el medio de cultivo empleado considerando la posible variación del tipo de MAP presente, "S" o "C", los que presentan una diferencia de requerimientos nutricionales para su crecimiento (Elguezabal et al., 2011; Whittington, 2011; Stevenson, 2015; Whittington et al., 2019), o al momento del proceso de la descontaminación bacteriana, donde se puede reducir el número de bacterias viables para su cultivo y aislamiento. El aislamiento y cultivo del microorganismo en ovinos es extremadamente difícil, siendo en rebaños ovinos que el cultivo fecal detecta menos de los casos clínicos y requiere más de 12 meses para su incubación según reportan Windsor (2015), así como Whittington, 2010.

La posterior confirmación e identificación de los aislamientos obtenidos de MAP por medio de PCR IS900, realizada a partir de los cinco cultivos obtenidos, confirmó la 
presencia de MAP. Algunos autores en la actualidad sugieren que la identificación de la bacteria por PCR sea realizada a partir de las muestras obtenidas de los tejidos, agilizando el tiempo de los resultados, sin depender directamente de los cultivos obtenidos, ya que los tiempos de diagnóstico se prolongan por las características propias del aislamiento de MAP, indicando que esta prueba presenta una similar eficacia con los cultivos (Kawaji et al., 2007; Nilsen et al., 2008; Whittington et al., 2019).

De acuerdo con autores como Kumthekar, et al., (2013) y Konbon (2018) el determinar el grado de infección de la enfermedad en los rebaños, permite establecer programas de control adecuados que impacten significativamente en el costo - beneficio; considerando principalmente la prueba - desecho. Pues ante la inviabilidad de desechar y considerando la poca disponibilidad de algunos productores para la vacunación de los rebaños, las medidas de control deben enmarcarse hacia un fortalecimiento de la bioseguridad.

Considerando así la separación temprana de los corderos y la eliminación de animales con signología inicial clínica de la enfermedad, puede ser una medida que impacte positivamente a la reducción de la prevalencia de la enfermedad (Robee, 2011; Windsor 2015). Haciendo hincapié en que profesionistas del sector salud animal y líderes del sector productivo tengan un conocimiento claro del grado de presencia e impacto de la enfermedad, tanto clínica, económicamente y de salud pública; logrando así propuestas de control (Roche, 2015; Windsor, 2015; Wittington et al., 2019)

\section{CONCLUSIÓN}

Se confirma la presencia del Mycobacterium avium subsp paratuberculosis como agente etiológico de la enfermedad clínica, además de observar la presencia elevada de frecuencia de animales seropositivos a MAP, en rebaños del Valle Central del estado de Aguascalientes, México. Lo cual la convierte en una patología de alto impacto en la producción ovina del estado.

\section{LITERATURA CITADA}

BALSEIRO A, Perez V, Juste R. 2019. Chronic regional intestinal inflammatory disease: A trans-species slow infection. Comparative Immunology, Microbiology and Infectious Diseases. 62:68-100. https://doi.org/10.1016/j.cimid.2018.12.001

BEGG D, Whinttington R. 2010. Paratuberculosis in Sheep. In: Paratuberculosis, Organism, Disease, Control. United Kingdom. CAB International. Pp.157-168. http://doi.org/10.1079/9781845936136.0157

CHÁVEZ G, Trigo TF, Svastova P, Pavlik P. 2004. Identificación del polimorfismo genético de aislamientos de Mycobacterium avium subsp. Paratuberculosis de caprinos del centro de México. Veterinaria México. 35:75-84. https://www.redalyc.org/pdf/423/42335107.pdf 
COELHO AC, Pinto ML, Coelho AM, Aires A, Rodríguez J. 2010. A seroepidemiological survey of Mycobacterium avium subsp. paratuberculosis in sheep from North of Portugal. Pesquisa Veterinária Brasileira. 30(11):903-908.

http://dx.doi.org/10.1590/S0100-736X2010001100001

DENNIS M, Reddacliff LA, Whittington RJ. 2011. Longitudinal study of clinicopathologycal features of Johne's diseases in sheep naturally exposed to Mycobacterium avium subs paratuberculosis. Veterinary. Pathology. 48:565-575.

http://dx.doi.org/10.1177/0300985810375049

DE JUAN L, Álvarez J, Romero B, Bezos J, Castellanos E, Aranaz A, Mateos A, Domínguez L. 2006. Comparison of four different culture media for isolation and growth of type II and type I/III Mycobacterium avium subsp. paratuberculosis strains isolated from cattle and goats. Applied and Environmental Microbiology. 72:5927-5932. http://dx.doi.org/10.1128/AEM.00451-06

ELGUEZABAL N, Bastida F, Sevilla IA, González N, Molina E, Garrido JM, Juste RA. 2011. Estimation of Mycobacterium avium subsp. paratuberculosis Growth Parameters: Strain Characterization and Comparison of Methods. Applied and Environmental Microbiology. 77: 8615-8624.

http://dx.doi.org/10.1128/AEM.05818-11

ESPESCHIT IF, Schwarz GG, Faria CS, Souza CC, Paolicchi FA, Juste RA, Carvalho IA, Moreira AS. 2017. Paratuberculosis in Latin America: a systematic review. Tropical Animal Health and Production. 49:1557-1576. http://dx.doi.org/10.1007/s11250-017$1385-6$

ESTÉVEZ DI, Hernández CR, Trujillo AM, Chávez GG. 2006. Detection of Mycobacterium avium subsp. Paratuberculosis in goat and sheep flocks in México. Small Ruminant Research. 72:209-213. http://dx.doi.org/10.1016/j.smallrumres.2006.10.017

FERNANDEZ SJ, Correa NM, Fernando RN. 2014. Systematic review of the prevalence of Paratuberculosis in cattle, sheep, and goats in Latin America and the Caribbean. Tropical Animal Health and Production. 46:1321-1340. http://dx.doi.org/10.1007/s11250014-0656-8

FERNANDEZ SF, Sánchez JM, Córdoba A, Largo AC. 2002. Estadística descriptiva. $2^{\text {da }}$ ed. Madrid, España: Editorial Esic. Pp. 566. ISBN: 978-847-35630-62 
GARCÍA MJ, Chávez G, Adúriz JJ, Pérez V, Juste RA, Badiola JJ. 1992. Prevalence of paratuberculosis in infected goat flocks and comparison of different methods of diagnosis. Proc. III Int. Coll. PTBC. 157-163. http://www.paratuberculosis.net/publications.php

GIOFFRÉ A, Correa MM, Alvarado PM, Vaca R, Morsella C, Fiorentino MA, Romano MI. 2015. Tipificación molecular de Mycobacterium avium subsp. paratuberculosis mediante análisis de repetición en tándem de número variable de múltiples locus. Revista Brasileña de Microbiología. 46:2: 557-564. https://doi.org/10.1590/S1517-838246220140283

JAIMES NG, Santillán FM, Hernández CO, Córdova LD, Guzmán RC, Arellano RB, Díaz AE, Tenorio GV, Cuéllar OA. 2008. Detección de Mycobacterium avium subespecie paratuberculosis, por medio de PCR-anidada a partir de muestras de heces de ovinos. Revista Veterinaria México. 39(4): 377-386.

https://www.redalyc.org/articulo.oa?id=42339402

KAWAJI S, Taylor DL, Mori Y, Whittington RJ. 2007. Detection of Mycobacterium Avium Subsp. paratuberculosis in ovine faeces by direct quantitative PCR has similar or greater sensitivity compared to radiometric culture. Veterinary Microbiology. 125:36-48. http://dx.doi.org/10.1016/j.vetmic.2007.05.002

KONBOON M, Bani YM, Pithua PO, Rhee N, Aly SS. 2018. A nested compartmental model to assess the efficacy of paratuberculosis control measures on US dairy farms. PLoS One. 13:10. https://doi.org/10.1371/journal.pone.0203190

KUMTHEKAR S, Manning EJ, Ghosh P, Tiwari K., Sharma RN, Hariharan H. 2013. Mycobacterium avium subespecie paratuberculosis confirmada tras la vigilancia serológica de pequeños rumiantes en Granada, West Indies. Revista de investigación de $\begin{array}{lll}\text { diagnóstico veterinario. 25(4): 527-530. } & \text {. }\end{array}$ https://journals.sagepub.com/doi/10.1177/1040638713490688

MEDEIROS JM, Garino JF, Torres MR, de Medeiros CV, Riet CF. 2012. Frequência de anticorpos para paratuberculose em bovinos no semiarido paraíbano. Pesquisa Veterinária Brasileira. 32:697-700. https://doi.org/10.1590/S0100-736X2012000800003

MEJíA MK, Lemus FC, González MC, Palomares RG, Díaz AE, Gutierréz HJ. 2015. Factores de riesgo asociados a Mycobacterium avium subsp. Paratuberculosis en rebaños ovinos de Nayarit, México. Revista Científica FCV-LUZ. 5:294-302.

https://www.redalyc.org/pdf/959/95953315005.pdf 
NIELSEN SS, Toft N. 2008. Ante mortem diagnosis of paratuberculosis: A review of accuracies of ELISA, interferon-gamma assay and fecal culture techniques. Veterinary Microbiology. 129:217-235. http://dx.doi.org/10.1016/j.vetmic.2007.12.011

NOM-033-SAG/ZOO-2014. Norma Oficial Mexicana: Métodos para dar muerte a los animales domésticos y silvestres. México. Diario Oficial de la Federación, 26/08/2014. https://www.dof.gob.mx/nota_detalle.php?codigo=5405210\&fecha=26/08/2015

OIE (World Organisation for Animal Healt). 2017. Manual of diagnostic test and vaccines for terrestrial animals Vol I. Recuperado en noviembre de 2017. http://www.oie.int/es/normas-internacionales/manual-terrestre/acceso-en-linea/

PÉREZ V, Tellechea J, Corpa JM, Gutiérrez M, García MJ. 1999. Relation between pathologic findings and cellular immune responses in sheep with naturally acquired Paratuberculosis. American Journal of Veterinary Research. 60:123-127. https://pubmed.ncbi.nlm.nih.gov/9918160/

ROCHE S, Jones BA, Meehan M, Massow M, Kelton D. 2015. Evaluating the effect of focus farms on Ontario dairy producers' knowledge, attitudes, and behaviour toward control of Johne's disease. J Dairy Sci. 98:5222-040. https://doi:10.3168/jds.2014-8765

ROBBE AS. 2011. Control of Paratuberculosisin Small Ruminants. Vet Clin Food Anim. 27:609-620.

https://doi:10.1016/j.cvfa.2011.07.007

SÁNCHEZ CC, Guerrero GC. 2006. Procedimientos en microbiología clínica. Recomendaciones de la Sociedad Española de Enfermedades Infecciosas y Microbiología Clínica. ISBN: 84-609-2287-1.

https://seimc.org/contenidos/documentoscientificos/procedimientosmicrobiologia/seimcprocedimientomicrobiologia1.pdf

SIAP (Servicio De Información Agroalimentaria Del Gobierno De México). 2018. Estadísticas de la producción pecuaria 2018. Recuperado en septiembre de 2018. http://infosiap.siap.gob.mx/gobmx/datosAbiertos.php

STEVENSON K. 2015. Genetic diversity of Mycobacterium avium subspecies paratuberculosis and the influence of strain type on infection and pathogenesis: a review. Veterinary Research. 46:64. http://dx.doi.org/10.1186/s13567-015-0203-2 
STRAUB OC. 2004. Maedi-Visna virus infection in sheep. History and present knowledge. Comparative Immunology. Microbiology and Infectious Diseases. 27:1-5. https://doi.org/10.1016/S0147-9571(02)00078-4

TIMONEY JF, Gillespie JH, Scott FW, Barlough JE. 1988. Hagan and Bruner's Microbiology and Infectious Diseases of Domestic Animals. Ithaca, United States: Cornell University Press. Pp. 912. ISBN: 9780-801-41896-9.

TRUSFIELD M. 2018. Veterinary Epidemiology. $4^{\text {ta }}$ ed. UK: Blackwell publishining. Pp. 888. ISBN: 978-1-118-28028-7.

WHITTINGTON RJ. 2010. Cultivation of Mycobacterium avium subsp. paratuberculosis. $2^{\text {da }}$ ed. Wallingford, UK. Editorial Cabi. Pp. 266-304. ISBN: 978-1-789-24341-3.

WHITTINGTON RJ, Marsh IB, Saunders V, Grant IR, Juste R, Sevilla IA, Manning EJ, Whitlock RH. 2011. Culture phenotypes of genomically and geographically diverse Mycobacterium avium subsp. paratuberculosis isolates from different hosts. Journal of Clinic Microbiology. 49:1822-1830. http://dx.doi.org/10.1128/JCM.00210-11

WHITTINGTON RJ, Donat K, Weber MF. 2019. Control of paratuberculosis: who, why and how. A review of 48 countries. BMC Veterinary Research. 15:198. http://dx.doi.org/10.1186/s12917-019-1943-4

WINDSOR PA. 2014. Managing control programs for ovine caseous lymphadenitis and paratuberculosis in Australia, and the need for persistent vaccination. Veterinary Medicine: Research and Reports. 5:11-22. https://doi.org/10.2147/VMRR.S44814

WINDSOR PA. 2015. Paratuberculosis in sheep and goats. Veterinary Microbiology. 181:161-9. http://dx.doi.org/10.1016/j.vetmic.2015.07.019 